\title{
Rarity of blister beetles (Coleoptera: Meloidae) in Southern Africa correlates with their phylogeny and trophic habits, but not body size
}

\author{
Monica PitZalis ${ }^{1}, V_{\text {alentina AMORE }}{ }^{1}$, Francesca MONTALTO $^{1}$, Luca LUISELli ${ }^{2}$ and Marco A. BOLOGNA ${ }^{1}$
}

\begin{abstract}
${ }^{1}$ Dipartimento di Scienze, Università degli Studi Roma Tre, Viale G. Marconi 446, 00146 Roma, Italy; e-mails: monica.pitzalis@uniroma3.it; valamore@bio.ucm.es; francescamontalto@hotmail.com; marco.bologna@uniroma3.it ${ }^{2}$ Institute of Environmental Studies, DEMETRA, Via Olona 7, I-00198 Rome, Italy; Department of Applied and Environmental Biology, Rivers State University of Science and Technology, Port Harcourt (Nigeria), and ENI s.p.a. Environmental Department (Nigerian Agip Oil Company Ltd.), via Lovanio 32, I-00198 Roma, Italy; e-mail: lucalui@iol.it
\end{abstract}

Key words. Coleoptera, Meloidae, biological rarity, southern Africa, xeric ecosystems

\begin{abstract}
Ecologists have identified several correlates of biological rarity in animals. Among the various correlates identified so far, three are explored in this paper: (a) abundance is correlated with absolute body size in animals; (b) phylogenetically primitive taxa are overrepresented in samples of rare species; (c) more specialized species are rarer than less specialized species. Here we use Namibian blister beetles (Coleoptera: Meloidae) as a model system for exploring these issues. We used data from five field expeditions, which resulted in the identification of 891 beetles belonging to 76 species collected from 191 sites. $13 \%$ of the species accounted for over $50 \%$ of the individuals; $22 \%$ of all species were represented by singletons. Abundance patterns differed significantly among the different trophic categories, with non-pollinophagous (non-specialized) species being more abundant than weed-eaters and pollinophagous (specialized) species. Species of phylogenetically basal tribes were less abundant than those of more derived groups. Trophic category and phylogenesis did not have a synergic effect in determining the relative abundance of the species, and body size had no influence on their abundance.
\end{abstract}

\section{INTRODUCTION}

The biology of rarity has received tremendous attention over the past two decades (Schoener, 1987; Gaston, 1994; Blackburn \& Gaston, 1997, 1999). Theoretical advances in the understanding of the biology of rarity has been due primarily to research on insects (Morse et al., 1988; Novotny, 1993; Price et al., 1995; Ulrich, 2001a, b), endothermic vertebrates (i.e., Cotgreave \& Pagel, 1997; Yu \& Dobson 2000; Harcourt et al., 2002), ectothermic vertebrates (Luiselli, 2006) as well as plants (Rabinowitz, 1981).

It has been demonstrated that, for example, there is a geographical bias in the distribution of animals (Schoener, 1987) with rare species more prevalent in the tropics than in temperate regions (Morse et al., 1988; Novotny, 1993; Stork et al., 1997). However, the above-mentioned patterns remain relatively controversial, with contrasting evidence from distinct datasets (e.g., Gaston, 1994). On the other hand, it is more evident that within each taxon large animals are usually scarcer than smaller ones (Cotgreave, 1993; Gaston, 1994; Blackburn \& Gaston, 1997, 1999; Spencer, 2000). For instance, this pattern occurs consistently in both African tropical and Asian tropical snake assemblages (Luiselli et al., 2005; Rahman et al., 2013). However, this pattern is likely to occur more frequently in assemblages of predators (due to limited resource availability) than of phytophagous organisms (Luiselli, 2006). In addition, rare species are often characterized by narrow realized ecological niches and high degrees of specialization (Gaston, 1996; Gaston \& Curnutt, 1998), and typically belong to phylogenetically old and/or primitive taxa
(Cotgreave \& Pagel, 1997). However, these latter patterns are difficult to test rigorously because few of the groups so far studied show such a remarkable diversity in terms of phylogeny and life-history traits (Gaston, 1994). Thus, it is important to find suitable model organisms that are sufficiently diverse in phylogeny and life-history traits to test for the occurrence of the above-mentioned patterns. In this regard, the beetle family Meloidae may be an ideal study system, given that it fulfills all the biological characteristics mentioned above (Bologna, 1991; Bologna et al., 2008b; Bologna \& Di Giulio, 2011). There has been no previous study on the biology of rarity in blister beetles.

Of the several hypotheses formulated to explain the biology of rarity we tested the following three key questions using data for Meloidae: (1) do abundance patterns correlate with absolute body size of animals, (2) are more specialized species (for instance, monophagous compared to polyphagous) rarer than less specialized species and (3) are some phylogenetically primitive taxa overrepresented among rare species? We tested these hypotheses by determining what aspects of the biology of beetles of the family Meloidae occurring in Namibia (Southern Africa) are correlated with their rarity. Meloid beetles are particularly suitable for this type of analysis because in tropical savannahs there are many species that are remarkably heterogeneous in terms of the parameters studied. In particular, Meloidae vary greatly in body size ( 3 to $70 \mathrm{~mm}$; Bologna et al., 2010), in their phylogeny, with three subfamilies and 15 tribes (Bologna et al., 2010) and feeding habits of the larval and adult stages (larvae are obligate parasites of both Hymenoptera Aculeata and Orthoptera Caelifera, and 
adults either pollinophagous, phyllophagous, or antophagous; Bologna, 1991; Bologna et al., 2010). In addition, in Namibia these species are active in open habitats over a relatively short period of time (from late January to early April), which minimizes any biases in collecting the different species due to differences in their phenology.

Ecologically, Namibia consists of xeric or sub-xeric biomes, namely the Namib desert, exclusive to this country and a small area in southern Angola, the Succulent and Nama Karoo, both of which extend in South Africa, Savannah which extends in Botswana and South Africa, and salt Pan (restricted to the Etosha plain) (e.g. Irish, 1994; Rutherford \& Westfall, 1994; Barnard, 1998). This area along with western South Africa is one of 25 hot spots of biodiversity recorded in the world (Myers et al., 2000). The great number of endemic taxa (especially species and genera) of plants and animals recorded there is the result of a long history of isolation and extreme ecological pressures of Namibian ecosystems (Jarvis \& Robertson, 1997; Barnard, 1998; Maggs et al., 1998; Simmons et al., 1998).

Our study is the first on the beetle fauna associated with arid open ecosystems in the tropics and provides further generalizations about the biology of rarity. There are similar studies by Siemann et al. (1999) on North American non-tropical grassland communities of arthropods.

\section{MATERIAL AND METHODS}

\section{Study area}

Research was conducted throughout almost the whole of Namibia at a total of 191 sites (Fig. 1). There are five main biomes in Namibia, which include several types of vegetation (e.g. Giess, 1971; White, 1983; Rutherford, 1997), all of which were extensively covered in this study. Tree and shrub savannahs are the most extensive ecosystems, while Succulent Karoo is restricted to a narrow area in the south-west, close to the mouth of the Orange River. The Namib desert extends along the sea cost and the Nama Karoo is diagonally wedge shaped and progressively narrows from South Africa to the Angolan border (Fig. 1). The climate of Namibia is primarily xeric, except in the north-eastern Caprivi strip and it rains from January to April (uncommonly in May) in most of the country and in Winter (August-October) in southwestern and southern central parts of the country or, occasionally, also in other areas (Tyson, 1986).

\section{Taxonomic model}

Meloidae is a family of phytophagous beetles, particularly rich in species in Afrotropical savannahs, which are characterized by hypermetabolic development and larval stages that parasitize Orthoptera Caelifera, Hymenoptera Apoidea and less frequently other Aculeata. Bologna (1991) and Bologna et al. (2008b) have studied the biology and phylogeny of this family and in particular the faunistics and taxonomy of the Namibian Meloidae were recently studied and updated by Bologna (2000, unpubl.).

\section{Field study}

Five expeditions, aimed at sampling most of the regions in this country were undertaken during the main rainy period (when host plants are in bloom) in 1997, 2001, 2003, 2004 and 2005. Each field expedition lasted on average 20 days. We know that this could potentially limit the value of this study as a few of the species (usually the most abundant ones: Bologna, unpublished database) may be occasionally active in other periods of the year

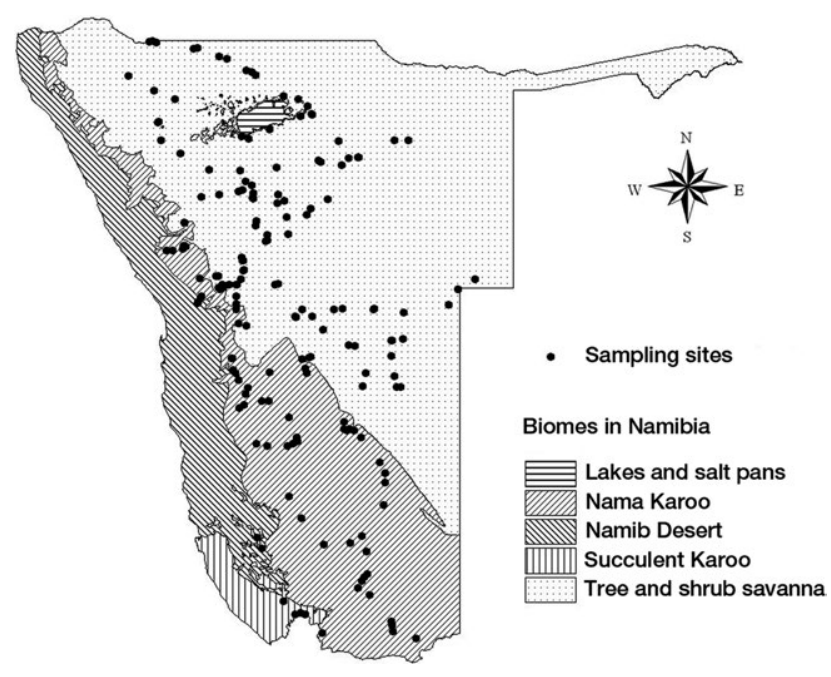

Fig. 1. Map of Namibia showing the distributions of the different biomes and location of the sites sampled.

and were therefore not sampled. However, it is unlikely that this greatly biased our results, because such occasional records are uncommon even among abundant species in the thousands of museums records for this country (Bologna et al., unpubl.). All the sites selected were within vegetation zones (Fig. 1) in which the habitat was extensively homogeneous. At each site, we standardized the field effort in order to minimize inter-site differences in the probability of capturing beetles. Hence, we spent $30 \mathrm{~min}$ collecting at each site, with three people actively patrolling flowering plants and collecting samples. As the three people walked at the same speed, approximately $1 \mathrm{~km}$ per hour, it is likely that the area surveyed at each site was nearly identical. All field collectors were experts on Namibian Meloidae and ecosystems (with over 10 years of field experience), which minimized sampling biases due to different catchabilities across sites and among species.

Insects were caught on host plants using a net or, at daybreak, also under house and petrol station lights, and afterwards identified to species at the laboratory in Rome, University 'Roma Tre'. Host plant was identified to family or genus (determined using keys, field guides and expert opinions of researchers associated with the National Museum of Windhoek), and the trophic category of each species was determined by direct observation of individuals in the field. The number of specimens collected for each species are the measures of species abundances used in this paper. Singletons are here defined as those species for which only a single individual was collected (see Gaston, 1994).

There are some shortcomings in this method of sampling, however, that should be taken into account when interpreting the emerging patterns. For instance, the plant species were not similarly abundant at all sites, which possibly introduced some biases, especially for the most specialized beetles. Moreover, differences in plant density at the different sites may have affected catchability and the estimates of insect abundance. However, a Kruskal-Wallis ANOVA revealed no significant differences in mean abundances of the various species across habitat types $\left(\chi^{2}\right.$ $=0.130, \mathrm{df}=3, \mathrm{p}=0.898)$, thus the results for the different sites were pooled in our analyses. In addition, we could not exclude that were fluctuations in population size from year to year in at least some species and at some sites.

\section{Analyses}

Each meloid species was assigned to a particular trophic category: (i) non-pollinophagous (feeding on every part of a flower, apart from pollen) (= non-specialized), (ii) pollinophagous (eat- 
TABLE 1. List of the Meloidae beetles of Namibia studied, including details of the number of specimens collected, tribe, trophic category, phylogenetic score and body size. Endemic/subendemic species are asterisked.

\begin{tabular}{|c|c|c|c|c|c|}
\hline Species & Tribe & $\begin{array}{l}\text { Number of } \\
\text { specimens }\end{array}$ & Trophic categories & $\begin{array}{l}\text { Phylogenetic } \\
\text { score }\end{array}$ & $\begin{array}{l}\text { Body size in } \mathrm{cm} \\
\text { (category) }\end{array}$ \\
\hline Actenodia chrysomelina & Mylabrini & 40 & non-pollinophagous & 5 & $1.1(1)$ \\
\hline Australytta rubrolineata* & Lyttini & 1 & weed-eater & 4 & $1.9(2)$ \\
\hline Australytta szekessyi & Lyttini & 4 & weed-eater & 4 & $1.3(1)$ \\
\hline Ceroctis amphibia & Mylabrini & 12 & non-pollinophagous & 5 & $1.2(1)$ \\
\hline Ceroctis angolensis & Mylabrini & 57 & non-pollinophagous & 5 & $1.1(1)$ \\
\hline Ceroctis braunsiana & Mylabrini & 7 & non-pollinophagous & 5 & $1.2(1)$ \\
\hline Ceroctis exclamationis & Mylabrini & 1 & non-pollinophagous & 5 & $1.1(1)$ \\
\hline Ceroctis aliena & Mylabrini & 13 & non-pollinophagous & 5 & $1.9(2)$ \\
\hline Ceroctis karroensis & Mylabrini & 8 & non-pollinophagous & 5 & $1.1(1)$ \\
\hline Ceroctis korana & Mylabrini & 9 & non-pollinophagous & 5 & $1.4(1)$ \\
\hline Ceroctis peringueyi & Mylabrini & 9 & non-pollinophagous & 5 & $1.6(2)$ \\
\hline Ceroctis spuria & Mylabrini & 2 & non-pollinophagous & 5 & $1.3(1)$ \\
\hline Ceroctis trifasciata* & Mylabrini & 40 & non-pollinophagous & 5 & $1.7(2)$ \\
\hline Cyaneolytta depressicornis & Epicautini & 1 & weed-eater & 3 & $2.4(2)$ \\
\hline Cyaneolytta granulipennis & Epicautini & 2 & weed-eater & 3 & $2.6(3)$ \\
\hline Cyaneolytta maculifrons & Epicautini & 1 & weed-eater & 3 & $2.7(3)$ \\
\hline Cyaneolytta resplendens & Epicautini & 1 & weed-eater & 3 & $2.3(2)$ \\
\hline Epicauta designata & Epicautini & 3 & weed-eater & 3 & $1.4(1)$ \\
\hline Epicauta ovampoa* & Epicautini & 2 & weed-eater & 3 & $1.7(2)$ \\
\hline Epicauta velata & Epicautini & 1 & weed-eater & 3 & $1.3(1)$ \\
\hline Hycleus amoenus & Mylabrini & 1 & non-pollinophagous & 5 & $0.7(0)$ \\
\hline Hycleus basibicinctus & Mylabrini & 4 & non-pollinophagous & 5 & $1.4(1)$ \\
\hline Hycleus benguellanus* & Mylabrini & 9 & non-pollinophagous & 5 & $1.1(1)$ \\
\hline Hycleus bifucatus & Mylabrini & 5 & non-pollinophagous & 5 & $1.7(2)$ \\
\hline Hycleus bissexguttatus & Mylabrini & 5 & non-pollinophagous & 5 & $1.5(1)$ \\
\hline Hycleus brincki & Mylabrini & 2 & non-pollinophagous & 5 & $1.2(1)$ \\
\hline Hycleus buqueti & Mylabrini & 11 & non-pollinophagous & 5 & $3(3)$ \\
\hline Hycleus burmeisteri & Mylabrini & 25 & non-pollinophagous & 5 & $1.7(2)$ \\
\hline Hycleus bushmanicus* & Mylabrini & 9 & non-pollinophagous & 5 & $0.7(0)$ \\
\hline Hycleus damarensis* & Mylabrini & 8 & non-pollinophagous & 5 & $1.3(1)$ \\
\hline Hycleus decoratus & Mylabrini & 39 & non-pollinophagous & 5 & $1.1(1)$ \\
\hline Hycleus dentatus & Mylabrini & 42 & non-pollinophagous & 5 & $1.3(1)$ \\
\hline Hycleus derosus & Mylabrini & 1 & non-pollinophagous & 5 & $2(2)$ \\
\hline Hycleus deserticolus & Mylabrini & 45 & non-pollinophagous & 5 & $1.1(1)$ \\
\hline Hycleus devylderi* & Mylabrini & 21 & non-pollinophagous & 5 & $0.7(0)$ \\
\hline Hycleus hilaris* & Mylabrini & 4 & non-pollinophagous & 5 & $1.3(1)$ \\
\hline Hycleus hybridus & Mylabrini & 34 & non-pollinophagous & 5 & $1.7(2)$ \\
\hline Hycleus jucundus & Mylabrini & 15 & non-pollinophagous & 5 & $1.1(1)$ \\
\hline Hycleus kochi* & Mylabrini & 14 & non-pollinophagous & 5 & $0.7(0)$ \\
\hline Hycleus matabele & Mylabrini & 14 & non-pollinophagous & 5 & $1.5(1)$ \\
\hline Hycleus peringueyi & Mylabrini & 4 & non-pollinophagous & 5 & $1(0)$ \\
\hline Hycleus pilosus & Mylabrini & 10 & non-pollinophagous & 5 & $1.3(1)$ \\
\hline Hycleus politus* & Mylabrini & 3 & non-pollinophagous & 5 & $0.5(0)$ \\
\hline Hycleus scalaris* & Mylabrini & 13 & non-pollinophagous & 5 & $3(3)$ \\
\hline Hycleus sp. n.* & Mylabrini & 1 & non-pollinophagous & 5 & $3.8(3)$ \\
\hline Hycleus surcoufi & Mylabrini & 2 & non-pollinophagous & 5 & $1.1(1)$ \\
\hline Hycleus svakopinus* & Mylabrini & 64 & non-pollinophagous & 5 & $1(0)$ \\
\hline Hycleus tinctus & Mylabrini & 49 & non-pollinophagous & 5 & $2.1(2)$ \\
\hline Hycleus transvaalicus & Mylabrini & 8 & non-pollinophagous & 5 & $1.3(1)$ \\
\hline Hycleus tricolor & Mylabrini & 13 & non-pollinophagous & 5 & $2.4(2)$ \\
\hline Hycleus villosus & Mylabrini & 1 & non-pollinophagous & 5 & $1.4(1)$ \\
\hline Hycleus windhoekanus* & Mylabrini & 12 & non-pollinophagous & 5 & $1.1(1)$ \\
\hline Iselma hobohmi* & Derideini & 1 & pollinophagous & 0 & $0.7(0)$ \\
\hline Iselma penrithae* & Derideini & 3 & pollinophagous & 0 & $1(0)$ \\
\hline Lydomorphus bisignatus & Lyttini & 33 & non-pollinophagous & 4 & $1.9(2)$ \\
\hline Lydomorphus karibibensis* & Lyttini & 12 & non-pollinophagous & 4 & $2.3(2)$ \\
\hline "Lydomorphus" mesembryanthem $i *$ & Lyttini & 5 & non-pollinophagous & 4 & $1.3(1)$ \\
\hline Lydomorphus mimus* & Lyttini & 9 & non-pollinophagous & 4 & $1.7(2)$ \\
\hline Lydomorphus optatus & Lyttini & 1 & non-pollinophagous & 4 & $1.6(2)$ \\
\hline Lydomorphus strangulatus & Lyttini & 3 & non-pollinophagous & 4 & $1.7(2)$ \\
\hline Lydomorphus thoracicus & Lyttini & 55 & non-pollinophagous & 4 & $1.9(2)$ \\
\hline Lydomorphus tibialis* & Lyttini & 7 & non-pollinophagous & 4 & $2.2(2)$ \\
\hline "Lytta" elegantula* & Eleticini & 4 & non-pollinophagous & 1 & $1.2(1)$ \\
\hline Mimesthes maculicollis & Mylabrini & 5 & non-pollinophagous & 5 & $1.2(1)$ \\
\hline Nemognatha vansoni & Nemognathini & 5 & pollinophagous & 2 & $0.8(0)$ \\
\hline Paractenodia glabra* & Mylabrini & 2 & non-pollinophagous & 5 & $0.5(0)$ \\
\hline Paractenodia namaquensis* & Mylabrini & 10 & non-pollinophagous & 5 & $0.6(0)$ \\
\hline Paractenodia parva & Mylabrini & 1 & non-pollinophagous & 5 & $0.9(0)$ \\
\hline Prionotolytta binotata & Lyttini & 6 & non-pollinophagous & 4 & $1(0)$ \\
\hline Prionotolytta hajekae* & Lyttini & 2 & non-pollinophagous & 4 & $1(0)$ \\
\hline Prionotolytta melanura & Lyttini & 17 & non-pollinophagous & 4 & $0.9(0)$ \\
\hline Prionotolytta streyi & Lyttini & 1 & non-pollinophagous & 4 & $1.1(1)$ \\
\hline Prolytta namibensis* & Lyttini & 3 & non-pollinophagous & 4 & $1.5(1)$ \\
\hline Zonitis notaticollis* & Nemognathini & 2 & pollinophagous & 2 & $1.2(1)$ \\
\hline Zonitodema viridipennis & Nemognathini & 1 & pollinophagous & 2 & $1(0)$ \\
\hline Zonitomorpha costata* & Nemognathini & 1 & pollinophagous & $\overline{2}$ & $1.5(1)$ \\
\hline
\end{tabular}




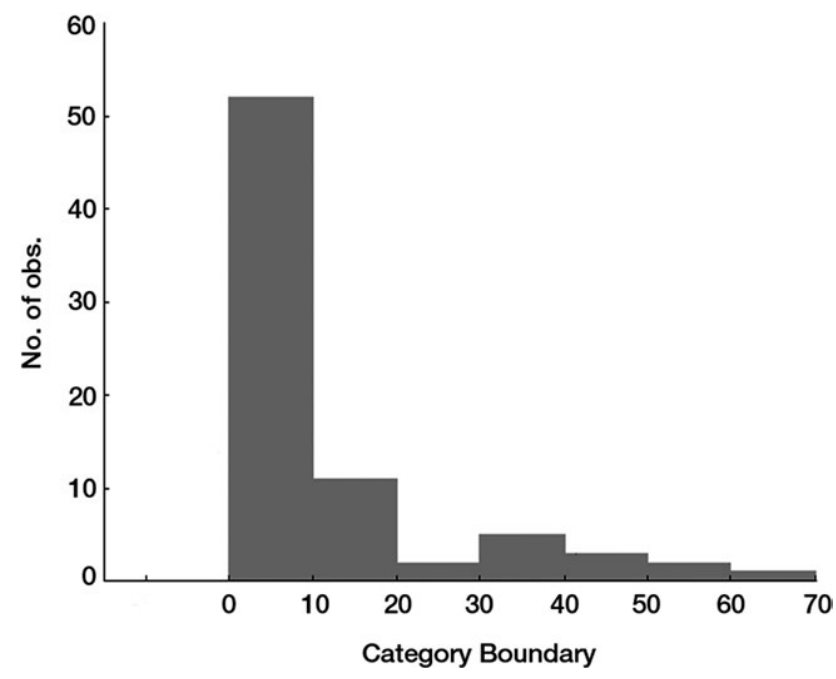

Fig. 2. Distribution of the numbers of individuals of species beetles belonging to the family Meloidae recorded in Namibia.

ing only pollen) or (iii) weed-eaters (feeding only on Poaceae) (both specialized). The assignment of each species to a particular trophic category was done using Bologna (2000, 2003), Bologna et al. (2001, 2008a), Bologna \& Di Giulio (2002), Amore (2005), Pitzalis \& Bologna (2008) and Marco A. Bologna's unpublished dataset. All nominal species listed belong to a single and distinct taxon and not to species complexes (Bologna, 2000). The species listed as Hycleus sp. n. is currently being described (Bologna, unpubl.).

The phylogenetic position of each species was defined based on Bologna et al. (2008b), which is a revision of this beetle family based on both morphological and molecular characters. We defined a "phylogenetic score" for each taxon, which increased in value from the base to the tips of the branches of the tree based on both Bayesian and Maximum Likelihood Tree analyses, which are strongly supported (see phylogeny in Bologna et al., 2008b). Unfortunately, it was not possible to extend this analysis to include the relationships between genera and species because the available information on phylogeny of Meloidae in Southern Africa is still rudimentary except for the genera Actenodia (Bologna et al., 2008a) and Iselma (Pitzalis \& Bologna, 2010). The basal taxa are those showing more symplesiomorphic conditions of molecular, morphological and biological traits (Hennig, 1967). All species belonging to the same tribe received an identical phylogenetic score: Derideini $=0$, Eleticini $=1$, Nemognathini $=2$, Epicautini $=3$, Lyttini $=4$, Mylabrini $=5$. Eupomphini, the sister group of Mylabrini (i.e. the last clade in the phylogenetic sequence) does not occur in Namibia, is a North American endemic taxon and therefore was not taken into consideration when determining the "phylogenetic score".

For each species, we determined the range in its body length (from apex of mandibles to apex of abdomen) by measuring a few thousand specimens in entomological collections (in particular: M.A. Bologna, Roma Tre University; National Museum of Namibia, Windhoek; Iziko South African Museum, Cape Town; Transvaal Museum, Pretoria; Museum für Naturkunde, Berlin). Each species was scored based on its body size as either: 0.5 $1.5 \mathrm{~cm}=1 ; 1.51-2.5 \mathrm{~cm}=2$ or $>2.50 \mathrm{~cm}=3$. In this context it should be taken into consideration that some species were in the past captured so rarely (e.g., 2 specimens of Zonitis notaticollis or Paractenodia glabra, for which only the types and the single individuals we collected are known; Bologna et al., unpubl. data) that it is likely the mean values differ in their accuracy.

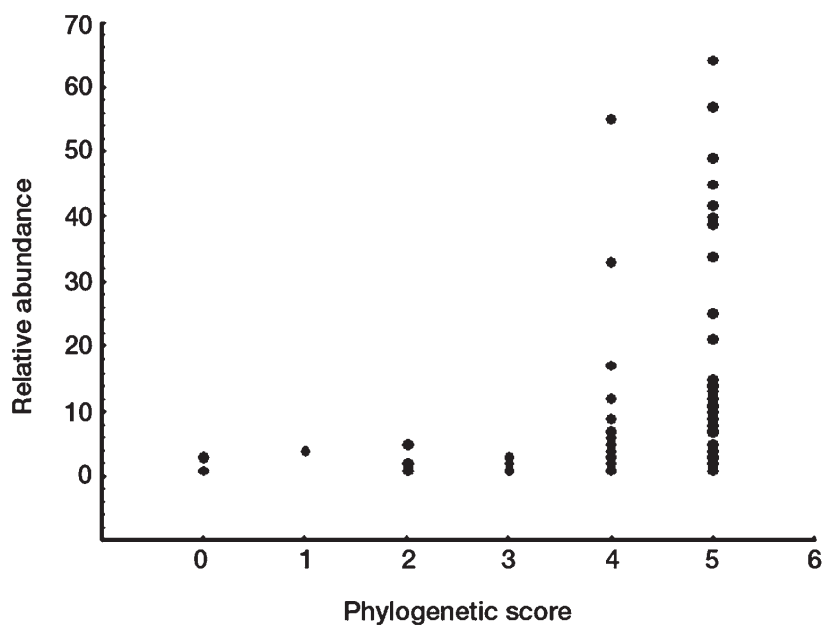

Fig. 3. Relationship between the relative abundances and phylogenetic scores of 76 species of Namibian Meloidae. The phylogenetic score varies from 0 to 5 , with the value increasing from basal to more derived taxa. For statistical details, see the text.

All data were checked for homoscedasticity and normality prior to applying parametric tests. Lilliefors test was used to determine the normality of the data. Chi-square tests were used to analyse differences in frequencies of occurrence among distinct groups of categories; Spearman's rank correlation coefficient was used to test correlation between two variables; a non-parametric ANOVA was used to evaluate the effects of trophic category $x$ phylogenetic score. Polynomial models (in the form of $y=a^{2}+$ $\mathrm{bx}+\mathrm{c}$ ) were used to explore the relationships between abundance and mean body size of species, taking into account the AICc values of the linear and polynomial models. Alpha was set at 5\%. All analyses were performed using Statistica 6.0 software.

\section{RESULTS}

In total, we collected 891 beetles belonging to 76 species. $35.5 \%$ of these species were endemic/subendemic (n $=27$ ), i.e. occurring only in Namibia or marginally also in northern South African Namaqualand or in Angolan western Kaokaland. We included the results for the whole group of Meloidae ( $\mathrm{n}=76$ species) in the analysis in order to increase the size of the samples and statistical power. The abundances recorded for all the species of blister beetles plus details of their feeding habits and phylogenetic position, are given in Table 1. Overall, the abundance distribution pattern was strongly uneven, with only 10 species (13\% of total) accounting for over $50 \%$ of the individuals and 20 species for well over $60 \%$ (Fig. 2). Thus, the main pattern was that there were few abundant and many uncommon or even rare species in the field. Singletons accounted for $22 \%$ of the total number of species recorded.

The great majority of the 76 species recorded were nonpollinophagous $(80.3 \%)$, with weed-eaters accounting for $11.8 \%$ and pollinophagous $7.9 \%$. Abundance of the species in the different trophic categories differed significantly, with non-pollinophagous species more abundant than pollinophagous and weed-eaters $\left(\chi^{2}=17.73\right.$, df $=2$, $\mathrm{p}=0.0001)$. There were 9 singletons among the non-pollinophagous species, 3 among pollinophagous and 5 among weed-eating species. The frequency of singletons differed 


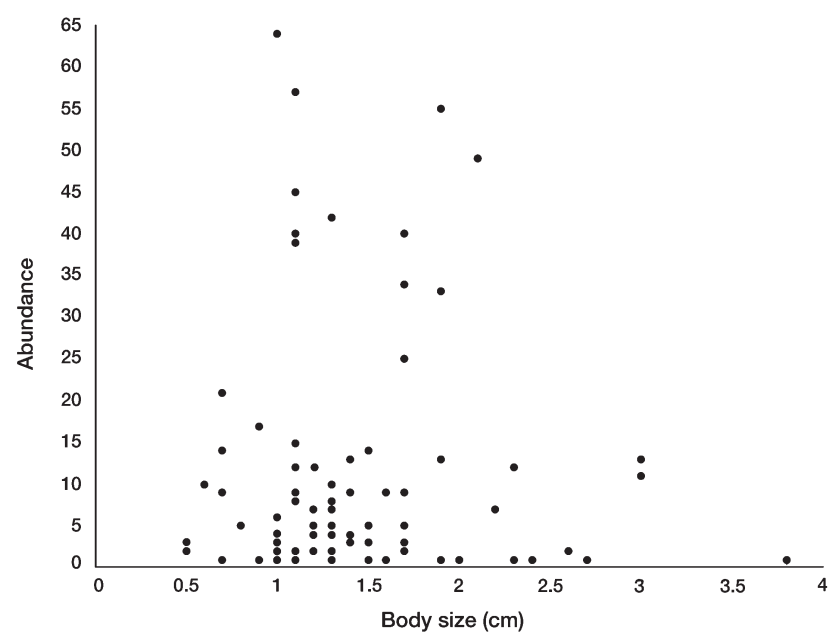

Fig. 4. Relationship between relative abundances and body sizes of beetles of the family Meloidae in Namibia.

significantly across the trophic categories $\left(\chi^{2}=16.33, \mathrm{df}=\right.$ $2, p<0.005)$, with significantly more singletons recorded among non-pollinophagous species $(52.9 \%$ of total were singletons) and they accounted for $80.3 \%$ of all the species recorded. Thus, we conclude that the number of singletons did not depend on trophic category per se, but merely on the number of species included in each trophic category.

Abundance of species in the different phylogenetic categories differed significantly, with Mylabrini species more abundant than those of other tribes $\left(\chi^{2}=17.62, \mathrm{df}=5, \mathrm{p}=\right.$ $0.0035)$. There was a statistically significant correlation between abundance and phylogenetic position (Spearman's $\mathrm{r}=0.441, \mathrm{n}=76, \mathrm{P}<0.00001$ ), with the more basal tribes less abundant than those of more derived tribes (Fig. 3). In terms of the number of singletons, their frequency was significantly correlated with the number of species included in each phylogenetic category (Spearman's $r=0.943, n=$ $5, \mathrm{P}=0.0048$ ).

A Kruskal-Wallis ANOVA revealed that neither the trophic category nor the phylogenetic score determined relative abundances of the species (trophic category: $\mathrm{H}$ $=0.553, \mathrm{P}=0.373$; phylogenetic score: $\mathrm{H}=0.196, \mathrm{P}=$ 0.884).

Beetle body size did not affect the abundances recorded (equation: $\mathrm{y}=3.502 \mathrm{x}^{2}+12.08 \mathrm{x}+2.899 ; \mathrm{AICc}=17007 ; \mathrm{r}^{2}$ $=0.02 ; \mathrm{H}=0.664, \mathrm{P}=0.498$ ) (Fig. 4).

\section{DISCUSSION AND CONCLUSION}

This study revealed several patterns. First, a few species dominated the samples and most of the other species were relatively less abundant. This pattern is quite general in the tropics (Lawton, 1991), recorded for snakes worldwide (Luiselli, 2006), amphibians in the Albertine Rift in East Africa (Behangana et al., 2009), arboreal beetles in Borneo (Morse et al., 1988), bugs in Indochina (Novotny, 1993) and canopy arthropods in general (Stork et al., 1997).

We also showed that non-pollinophagous species and those belonging to the tribe Mylabrini are more abundant than those of other trophic categories sampled. This undoubtedly is a consequence of an auto-correlation, given that (i) the Mylabrini is the most speciose group of Meloidae (Bologna et al., 2010), (ii) all Mylabrini are nonpollinophagous (Bologna, 1991) and (iii) the majority of Namibian non-pollinophagous species belong to the tribe Mylabrini (Table 1). Why were the non-pollinophagous species in our samples more abundant than the pollinophagous species? We consider that this is because pollinophagy is a highly specialized way of feeding, which requires specialized mouthparts (Bologna, 1991). According to general theory, ecological specialists should be rarer than non-specialized organisms (Gaston, 1994, 1996; Gaston \& Curnutt, 1998). Hence, it is not surprising that Derideini and Nemognathini (basal groups within Meloidae) were less frequently recorded in our samples. A greater incidence of rarity among specialist species is recorded for snakes (Luiselli, 2006). However, it is still possible that the abundance of non-pollinophagous species may simply reflect factors promoting diversity in Mylabrini that differ for pollinophagous species.

Singletons followed expected trends in abundance and diversity, that is, there were more singletons among nonpollinophagous species of Mylabrini. Hence, it is likely to be a by-product of chance (relative numbers of individuals in the samples) and does not merit further discussion. Novotny \& Basset (2000) found a relationship between monophagous habits (host-specificity) and probability of the occurrence of singletons, a relationship not apparent in our results. For instance, all Mylabrini singletons in our samples were not strictly monophagous. In any case, recent studies also show that dispersal should be taken into account when interpreting the abundance of singletons in complex communities of organisms (Ulrich \& Zalewski, 2006). Cotgreave \& Pagel's (1997) hypothesis that rare species are mainly phylogenetically basal species was indeed confirmed by our analyses, whereas this was not indicated by some earlier studies on other types of organisms (e.g., Luiselli, 2006). Surprisingly, however, large species were not rarer in our samples, despite the prediction of general theory (Gaston, 1994; Blackburn \& Gaston, 1997, 1999) and some evidence from other studies (e.g., snakes, see Luiselli, 2006).

Despite the distinct patterns in the correlates of abundance in Namibian blister beetles presented in this paper, nonetheless it should be noted that a major difficulty in evaluating rarity and abundance patterns is that there is no widely accepted definition of rarity and the issue is even controversial (Gaston, 1994; Kunin \& Gaston, 1997; Ulrich, 2001a; Harcourt et al., 2002; Luiselli, 2006). For instance, the method of collecting used, behaviour of the species (not all the species are equally cryptic), time of sampling (i.e., season or time of day) and size of the species may affect their rate of capture and so result in a greater likelihood of one species being captured than another (Gaston, 1994; Luiselli, 2006). Hence, it is likely that the same problems may need to be taken into account when considering the data presented herein.

ACKNOWLEDGEMENTS. We wish to thank P. Audisio, M. Biondi, M. Bologna, P. Bombi, C. Marangoni, E. Marais and M. 
Zapparoli for their help with collecting specimens in Namibia; two anonymous referees considerably improved the submitted draft.

\section{REFERENCES}

AMORE V. 2005: Ricerche autoecologiche e sinecologiche sui Coleotteri Meloidi della Namibia. Master thesis, University Roma Tre, Rome, 200 pp.

Barnard P. 1998: Biological Diversity in Namibia: A Country Study. Namibian National Biodiversity Task force, Windhoek, $332 \mathrm{pp}$.

Behangana M., Kasoma P.M.B. \& Luiselli L. 2009: Ecological correlates of species richness and population abundance patterns in the amphibian communities from the Albertine Rift, East Africa. - Biodivers. Conserv. 18: 2855-2873.

BlackBURN T.M. \& GASTON K.J. 1997: A critical assessment of the form of the interspecific relationship between abundance and body size in animals. - J. Anim. Ecol. 66: 233-249.

BlackbuRn T.M. \& Gaston K.J. 1999: The relationship between animal abundance and body size in natural animal assemblages. - J. Anim. Ecol. 62: 519-528.

Blackburn T.M., Brown V.K., Doube B.M., Greenwood J.J.D., LAWTON J.H. \& Stork N.E. 1993: The relationship between abundance and body size in natural animal assemblages. $-J$. Anim. Ecol. 62: 519-528.

Bologna M.A. 1991: Coleoptera Meloidae, Fauna d'Italia. XXIII. Calderini, Bologna, 541 pp.

Bologna M.A. 2000: Biodiversity of the Meloidae (Coleoptera) of the Brandberg Massif (Namibia). Cimbebasia Memoir 9: 201-208.

Bologna M.A. 2003: Australytta, a new blister beetle genus from Southern Africa (Coleoptera: Meloidae). - Ann. Soc. Entomol. Fr. 39: 139-152.

Bologna M.A. \& Di Giulio A. 2002: Review of the Southern African genus Prolytta Kaszab, with a description of the first instar larva, and bionomic and taxonomic remarks (Coleoptera, Meloidae). — Invertebr. Syst. 16: 177-194.

Bologna M.A. \& Di Giulio A. 2011: Biological and morphological adaptations in the pre-imaginal phases of the beetle family Meloidae. - Atti Accad. Naz. Ital. Entomol. 59: 141-152.

Bologna M.A., Fattorini S. \& Pinto J.D. 2001: Review of the primitive blister beetle genus Iselma with description of the first instar larva (Coleoptera: Tenebrionoidea: Meloidae). Afr. Entomol. 9: 105-129.

Bologna M.A., Di Giulio A. \& Pitzalis M. 2008a: Systematics and biogeography of the genus Actenodia (Coleoptera: Meloidae: Mylabrini). - Syst. Entomol. 33: 319-360.

Bologna M.A., Oliverio M., Pitzalis M. \& Mariottini P. 2008b: Phylogeny and evolutionary history of blister beetles (Coleoptera, Meloidae). - Mol. Phylogen. Evol. 48: 679-693.

Bologna M.A., Turco F. \& Pinto J.D. 2010: Meloidae Gyllenhal 1810. In Leschen R.A.B., Beutel R.G. \& Lawrence J.F. (eds): Handbook of Zoology. Coleoptera, Beetles, Vol. 2: Morphology and Systematics (Elateroidea, Bostrichiformia, Cucujiformia partim). De Gruyter, Berlin/New York, pp. 681-693.

Cotgreave P. 1993: The relationship between body size and population abundance in animals. - Tree 8: 244-248.

Cotgreave P. \& Pagel M. 1997: Predicting and understanding rarity: the comparative approach. Kunin W. \& Gaston K. (eds): The Biology of Rarity: The Causes and Consequences of Rarecommon Differences Chapman and Hall, London, pp. 237-261.

Gaston K.J. 1994: Rarity. Chapman \& Hall, London, 201 pp.

Gaston K.J. 1996: The multiple forms of the interspecific abundance-distribution relationship. _ Oikos 76: 211-220.
Gaston K.J. \& CuRnutT J.L. 1998: The dynamics of abundancerange size relationships. - Oikos 81: 38-44.

GIEss W. 1971: A preliminary vegetation map of Namibia. Dinteria 4: 1-114.

Harcourt A.H., Coppeto S.A. \& Parks S.A. 2002: Rarity, speciation and extinction in primates. - J. Biogeogr. 29: 445-456.

HenNIG W. 1967: Untersuchungen zur Struktur und Funktion des Lampenbfirsten-Y-Chromosoms in der Spermatogenese von Drosophila. - Chromosoma 22: 290-357.

IRISH J. 1994: Biomes of Namibia. — Navorsinge Nasion. Mus. Bloemfontein 10: 549-592.

JARVIS A.M. \& Robertson A. 1997: Endemic Birds of Namibia: Evaluating their Status and Mapping Biodiversity Hotspots. Research Discussion Paper 14, Directorate of Environmental Affairs, Ministry of Environment and Tourism, Windhoek, 122 pp.

Kunin W.E. \& Gaston K.J. 1997: The Biology of Rarity. Chapman \& Hall, London, 280 pp.

LAWTON J.H. 1991: Species richness, population abundances, and body sizes in insect communities: tropical versus temperate comparisons. In Price P.W., Lewinsohn T.M., Fernandes G.W. \& Benson W.W. (eds): Plant-Animal Interactions: Evolutionary Ecology in Tropical and Temperate Regions. John Wiley \& Sons, New York, pp. 71-89.

LUISELLI L. 2006: Testing hypotheses on the ecological patterns of rarity using a novel model of study: snake communities worldwide. - Web Ecol. 6: 44-58.

Luiselli L., Akani G.C., Rugiero L. \& Politano E. 2005: Relationships between body size, population abundance and niche characteristics in the community of snakes from three habitat in southern Nigeria. - J. Zool. (London) 265: 207-213.

Maggs G.L., Craven P. \& Kolberg H.H. 1998: Plant species richness, endemism, and genetic resources in Namibia. - Biodivers. Conserv. 7: 435-446.

Morse D.R., Stork N.E. \& LaWton J.H. 1988: Species number, species abundance and body length relationships of arboreal beetles in Bornean lowland rainforest trees. - Ecol. Entomol. 13: $25-37$.

Myers N., Mittermeier R.A., Mittermeier C.G., Da Donseca G.A.B. \& KenTS J. 2000: Biodiversity hot spots for conservation priorities. - Nature 403: 853-858.

Novotny V. 1993: Spatial and temporal components of species diversity in Auchenorrhyncha (Insecta: Hemiptera) communities of Indochinese montane rain forest. - J. Trop. Ecol. 9: 93-100.

Novotny V. \& Basset Y. 2000: Rare species in communities of tropical insect herbivores: pondering the mystery of singletons. —Oikos 89: 564-572.

Pitzalis M. \& Bologna M.A. 2008: Taxonomy and faunistics of the southern African genus Iselma, with the description of nine new species (Coleoptera: Meloidae: Eleticinae). — Zootaxa 1876: 39-59.

Pitzalis M. \& Bologna M.A. 2010: Time of diversification in the Cape fauna endemisms, inferred by phylogenetic studies of the genus Iselma (Coleoptera: Meloidae: Eleticinae). - Syst. Entomol. 35: 739-752.

Price P.W., Diniz I.R., Morais H.C. \& Marques E.S.A. 1995: The abundance of insect herbivore species in the tropics: the high local richness of rare species. - Biotropica 27: 468-478.

Rabinowitz D. 1981: Seven form of rarity. In Synge H. (ed.): The Biological Aspects of Rare Plant conservation. John Wiley \& Sons, New York, pp. 205-217.

Rahman S.C., Rashid S.M.A., Das K. \& Luiselli L. 2013: Composition and structure of a snake assemblage in an altered 
tropical forest-plantation mosaic in Bangladesh. - AmphibiaReptilia 34: 41-50.

RUTHERFORD M.C. 1997: Characterization of biomes. In Cowling R.M., Richardson D.M. \& Pierce S.M. (eds): The Vegetation of Southern Africa. Cambridge University Press, Cambridge, pp. 91-98.

Rutherford M.C. \& Westfall R.H. 1994: Biomes of southern Africa: an objective categorization. - Mem. Bot. Surv. Sth Afr. 63: $1-94$.

SCHOENER T.W. 1987: The geographical distribution of rarity. Oecologia 74: 161-173.

Siemann E., Tilman D. \& HaArstad J. 1999: Abundance, diversity and body size: patterns from a grassland arthropod community. - J. Anim. Ecol. 68: 824-835.

Simmons R.E., Griffin M., Griffin R.E., Marais E. \& Kolberg H. 1998: Endemism in Namibia: patterns, processes and predictions. - Biodivers. Conserv. 7: 513-530.

SPENCER M. 2000: Are predators rare? - Oikos 89: 115-122.
Stork N.E., Adis J. \& Didham R.K. 1997: Canopy Arthropods. Chapman \& Hall, London, 567 pp.

Tyson P.D. 1986: Climatic Change and Variability in Southern Africa. Oxford University Press, Cape Town, 220 pp.

UlRICH W. 2001a: Ecological characteristics of rare species: the case of parasitic Hymenoptera. - Pol. J. Ecol. 49: 379-389.

UlRICH W. 2001b: Relative abundance distributions of species: the need to have a new look at them. - Pol. J. Ecol. 49: 391405.

UlRich W. \& ZaLewSKI M. 2006: Abundance and co-occurrence patterns of core and satellite species of ground beetles on small lake islands. - Oikos 114: 338-348.

White F. 1983: The Vegetation of Africa. UNESCO, Paris, 356 pp.

Yu J. \& Dobson F.S. 2000: Seven forms of rarity in mammals. J. Biogeogr. 27: 131-139.

Received November 18, 2013; revised and accepted May 5, 2014 Prepublished online August 13, 2014 